\title{
Manganese Deficiency in Palms ${ }^{1}$
}

Timothy K. Broschat ${ }^{2}$

\section{Symptoms}

The newest leaves of manganese (Mn)-deficient palms emerge chlorotic with longitudinal necrotic streaks (Figures 1 and 2). As the deficiency progresses, newly emerging leaflets appear necrotic and withered on all but basal portions of the leaflets. This withering results in a curling of the leaflets about the rachis giving the leaf a frizzled appearance ("frizzletop") (Figures 3 through 6). Within a single leaf, Mn deficiency symptoms are concentrated at the base of the leaf and are less severe or nonexistent towards the tip (Figure 7). On new leaves of Mn-deficient Cocos nucifera (coconut palm), necrotic leaflet tips fall off and the leaf has a singed appearance (Figure 8). In severely Mn-deficient palms, growth stops and newly emerging leaves consist solely of necrotic petiole stubs (Figure 9). Palm death usually follows.

\section{Cause}

Manganese deficiency is caused by insufficient $\mathrm{Mn}$ in the soil or by high soil $\mathrm{pH}$, which greatly reduces $\mathrm{Mn}$ availability (Figure 3 ). In soils where $\mathrm{Mn}$ is marginally sufficient, cold soil temperatures may cause temporary Mn deficiency by reducing root

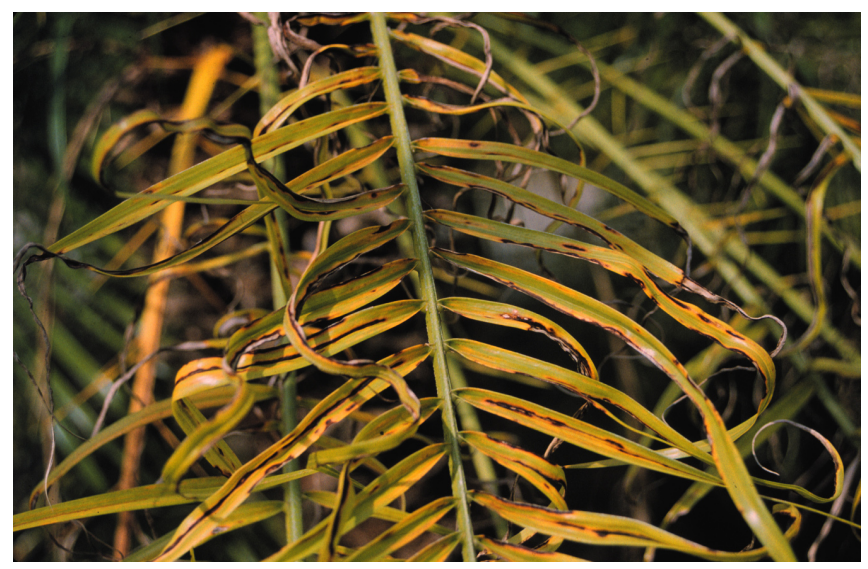

Figure 1. Manganese deficient new leaf of Phoenix roebelenii showing longitudinal necrotic streaking. Credits: T.K. Broschat

activity levels. This is particularly common on Cocos nucifera in Florida. Composted sewage sludge and manure products have also been shown to strongly bind $\mathrm{Mn}$ when used as fertilizers or as soil amendments for palms (Figure 8).

\section{Occurrence}

Manganese deficiency is very common on alkaline soils, but can occur in containers if drainage is poor or soil temperatures are cool. Most species of palms can be affected, but Syagrus romanzoffiana

1. This document is ENH1015, one of a series of the Environmental Horticulture Department, Florida Agricultural Experiment Station, Florida Cooperative Extension Service, Institute of Food and Agricultural Sciences, University of Florida. Original publication date September 14, 2005. Visit the EDIS Web Site at http://edis.ifas.ufl.edu.

2. Timothy K. Broschat is Professor, Environmental Horticulture Department, Fort Lauderdale Research and Education Center, Institute of Food and Agricultural Sciences, University of Florida, Fort Lauderdale, FL 33314

The Institute of Food and Agricultural Sciences (IFAS) is an Equal Opportunity Institution authorized to provide research, educational information and other services only to individuals and institutions that function with non-discrimination with respect to race, creed, color, religion, age, disability, sex, sexual orientation, marital status, national origin, political opinions or affiliations. U.S. Department of Agriculture, Cooperative Extension Service, University of Florida, IFAS, Florida A. \& M. University Cooperative Extension Program, and Boards of County Commissioners Cooperating. Larry Arrington, Dean 


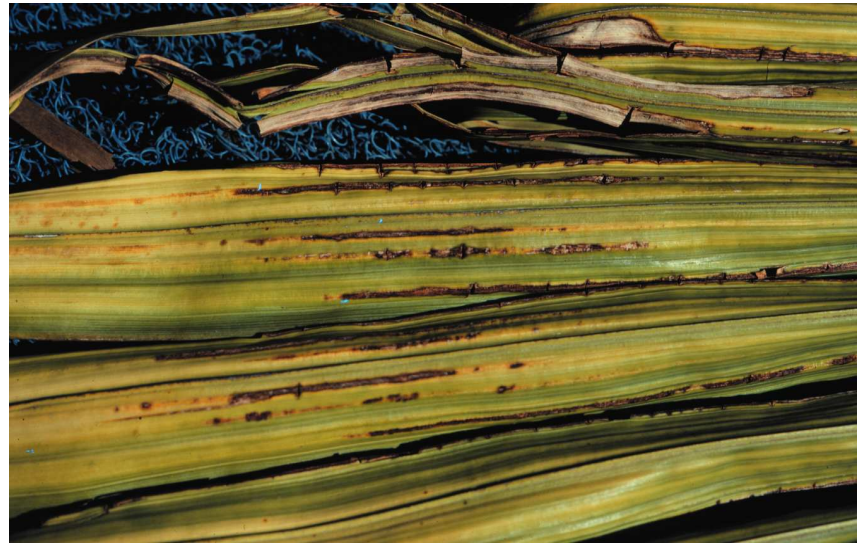

Figure 2. Leaflets on youngest leaf of Mn-deficient Archontophoenix alexandrae (Alexandra palm). Note longitudinal necrotic streaking on chlorotic leaflets. Credits: T.K. Broschat

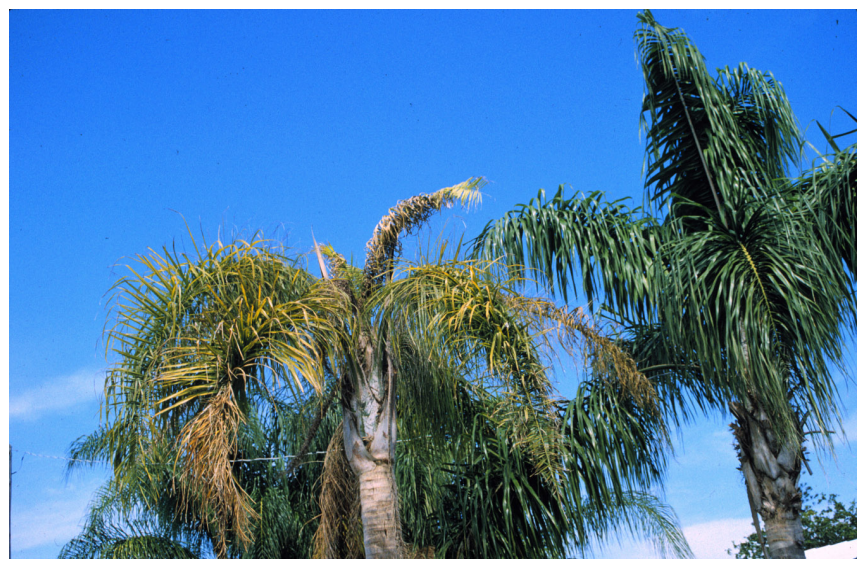

Figure 3. Manganese deficiency or "frizzletop" on Syagrus romanzoffiana caused by high soil $\mathrm{pH}$. Note that old leaves are full size, while young leaves are greatly reduced in size. Credits: T.K. Broschat

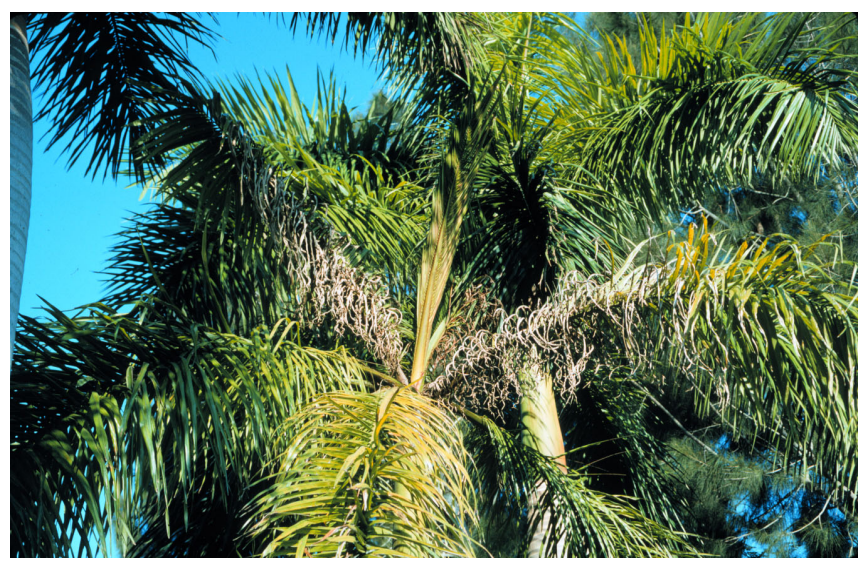

Figure 4. Manganese deficiency on Roystonea regia (Cuban royal palm). Credits: T.K. Broschat

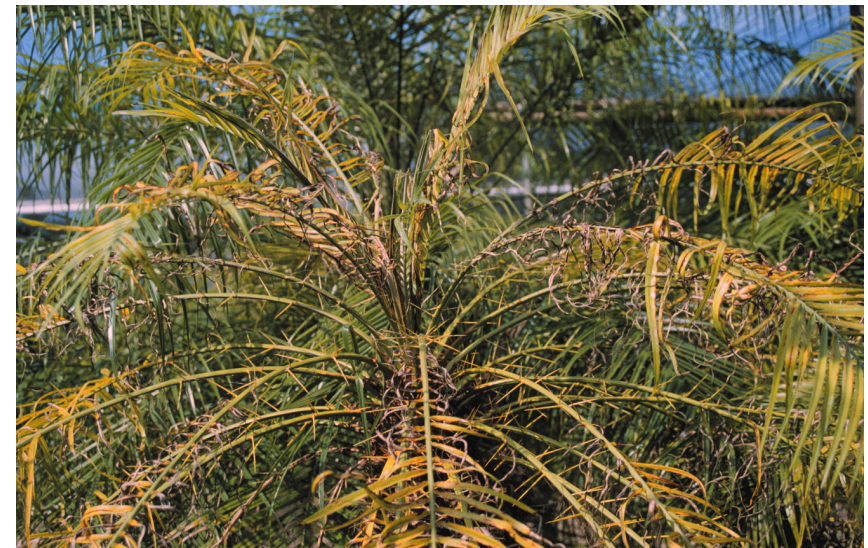

Figure 5. Manganese deficiency on Phoenix roebelenii. Credits: T.K. Broschat

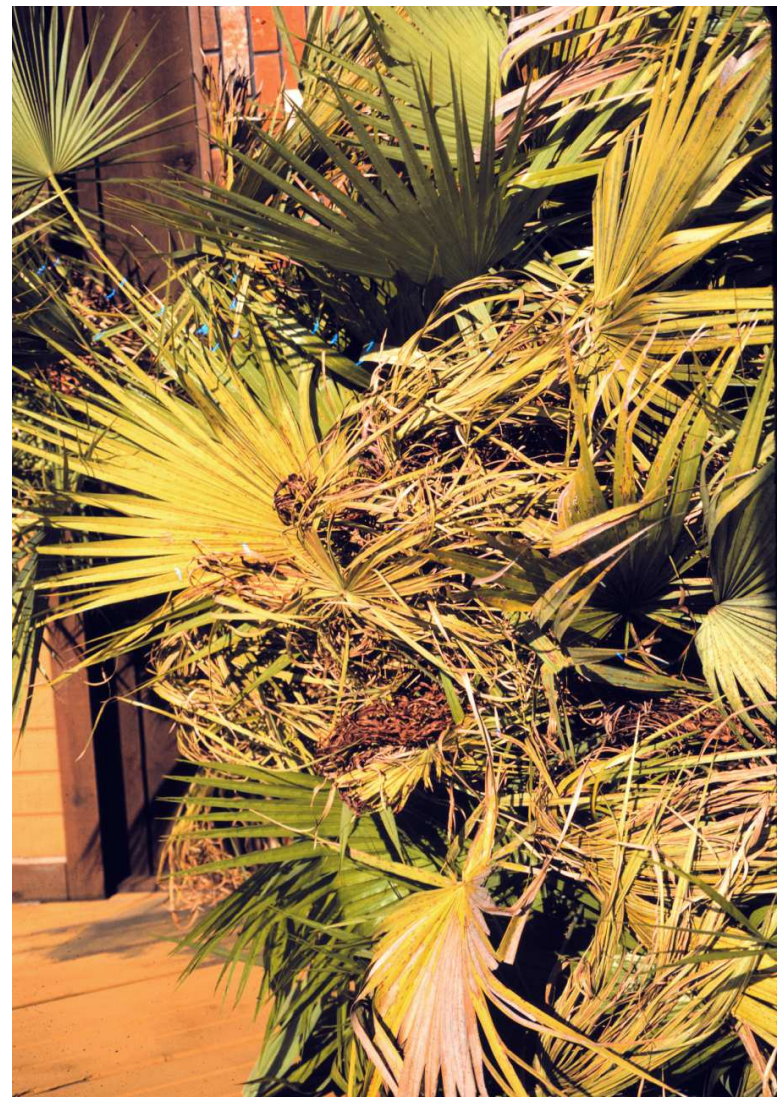

Figure 6. Manganese deficiency or "frizzletop" of Acoelorrhaphe wrightii. Credits: T.K. Broschat

(queen palm), Acoelorrhaphe wrightii (paurotis palm), Phoenix roebelenii (pygmy date palm), and Elaeis guineensis (African oil palm) are particularly susceptible.

\section{Diagnostic Techniques}

Visual symptoms may be sufficient to diagnose this disorder, but leaf nutrient analysis is also suggested, since symptoms of boron (B) deficiency 


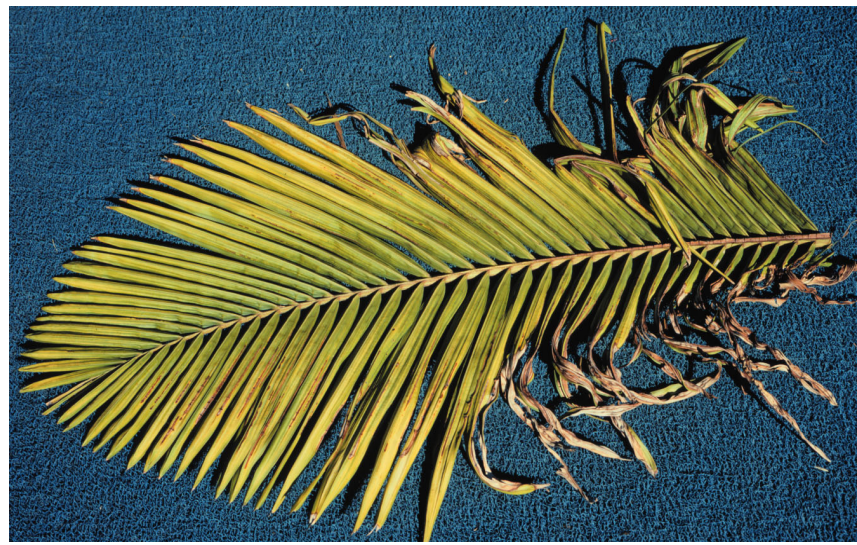

Figure 7. New leaf of Mn-deficient Archontophoenix alexandrae showing more severe symptoms towards the leaf base. Credits: T.K. Broschat

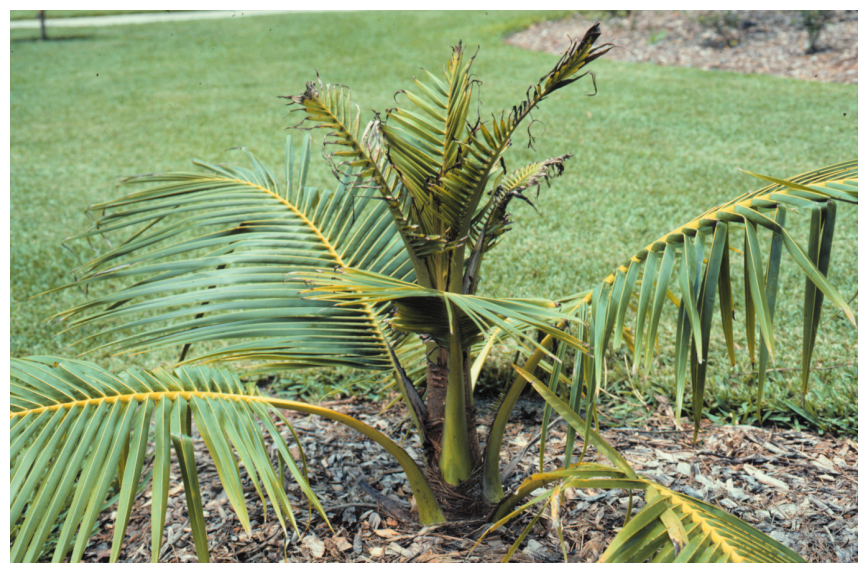

Figure 8. Manganese deficiency on Cocos nucifera induced by composted sewage sludge in the backfill. Credits: T.K. Broschat

can be similar. Late stage potassium (K) deficiency symptoms are virtually indistinguishable from those of Mn deficiency at a distance and close examination is required to look for characteristic longitudinal streaking and basal (vs distal) symptom distribution of Mn deficiency.

When sampling for leaf analysis, select 4 to 6 central leaflets from the youngest fully-expanded leaf. Soil analysis is not particularly useful for diagnosing palm nutrient deficiencies, since palm nutrient symptomology often bears little resemblance to soil nutrient profiles.

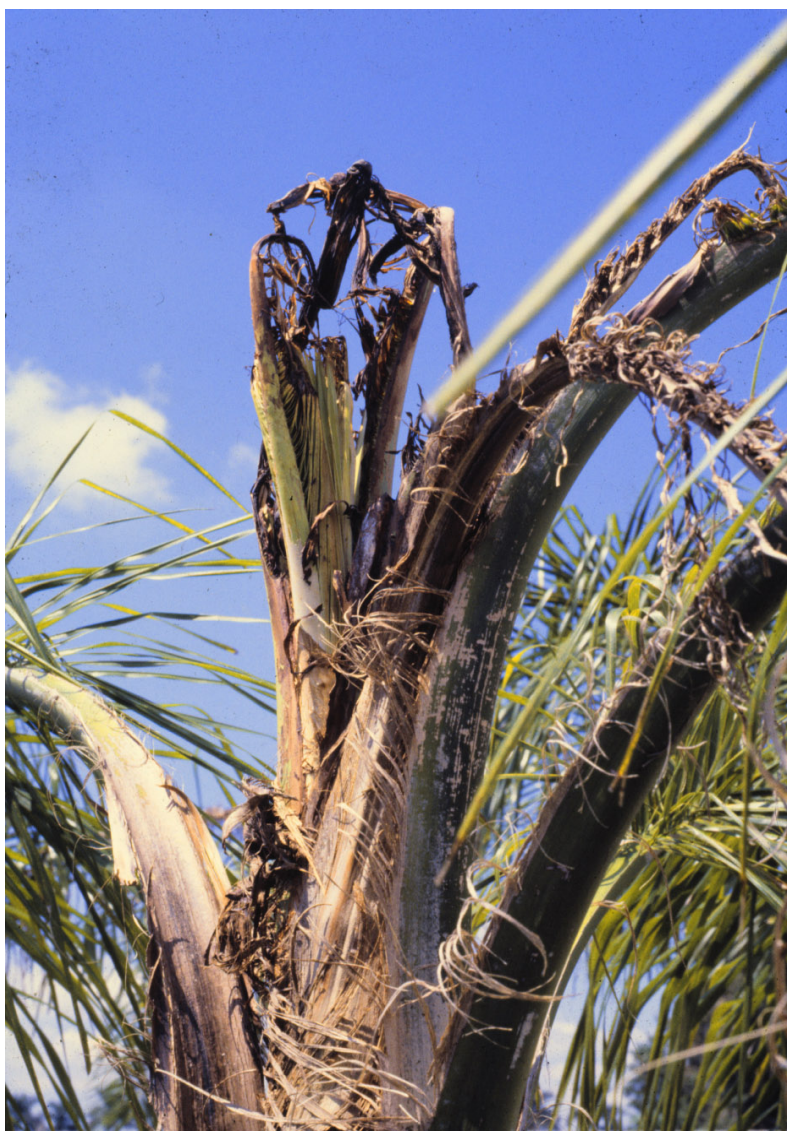

Figure 9. Severe Mn deficiency in Syagrus romanzoffiana. Credits: T.K. Broschat

\section{Management}

Fertilizers containing water soluble Mn should be used routinely on soils where Mn deficiency is a problem. Although soil applications of manganese sulfate are effective, spraying the foliage with this product may achieve more rapid, though short-term results, especially on alkaline soils. This should be considered as a supplement to soil applications, not as a replacement. Manganese sulfate solutions to be applied to the foliage can be made by mixing $3 \mathrm{lbs}$ of this product in 100 gals of water. Soil application rates are dependent on palm species, soil type, and severity of Mn deficiency. These rates will range from as low as $8 \mathrm{oz}$ for a small palm or one growing on an acid sand soil to $8 \mathrm{lbs}$ for a large palm growing on a limestone soil. Broadcast this product over the soil under the palm canopy. Applications can be repeated every 2 to 3 months, depending on the severity of the problem and soil type. However, a response may not be seen until 3 to 6 months after applications. Avoid using composted sewage sludge or manure products near palms. Excessive Mn 
applications normally result in an induced $\mathrm{Fe}$

deficiency, with its characteristic new leaf chlorosis.

\section{Selected References}

Broschat, T.K. 1984. Nutrient deficiency symptoms in five species of palms grown as foliage plants.

Principes 28:6-14.

Broschat, T.K. 1991a. Manganese binding by municipal waste composts used as potting media. J. Environ. Hort. 9:97-100.

Broschat, T.K. 1991b. Effects of manganese source on manganese uptake by pygmy date palms.

HortScience 26:1389-1391.

Bull, R.A. 1961. Studies on the deficiency diseases of the oil palm. 3. Micronutrient deficiency symptoms in oil palm seedlings grown in sand culture. J. West African Inst. Oil Palm Res. 3:265-272. 